\title{
Cutting the cost of carbon capture: a case for carbon capture and utilization $\dagger$
}

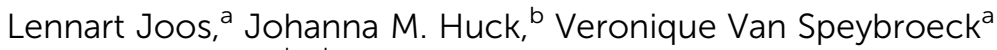 \\ and Berend Smit*bcd
}

Received 29th February 2016, Accepted 11th March 2016

DOI: $10.1039 / c 6 f d 00031 b$

A significant part of the cost for carbon capture and storage (CCS) is related to the compression of captured $\mathrm{CO}_{2}$ to its supercritical state, at 150 bar and typically $99 \%$ purity. These stringent conditions may however not always be necessary for specific cases of carbon capture and utilization (CCU). In this manuscript, we investigate how much the parasitic energy of an adsorbent-based carbon capture process may be lowered by utilizing $\mathrm{CO}_{2}$ at 1 bar and adapting the final purity requirement for $\mathrm{CO}_{2}$ from $99 \%$ to $70 \%$ or $50 \%$. We compare different $\mathrm{CO}_{2}$ sources: the flue gases of coalfired or natural gas-fired power plants and ambient air. We evaluate the carbon capture performance of over 60 nanoporous materials and determine the influence of the initial and final $\mathrm{CO}_{2}$ purity on the parasitic energy of the carbon capture process. Moreover, we demonstrate the underlying principles of the parasitic energy minimization in more detail using the commercially available NaX zeolite. Finally, the calculated utilization cost of $\mathrm{CO}_{2}$ is compared with the reported prices for $\mathrm{CO}_{2}$ and published costs for CCS.

\section{Introduction}

Nowadays, there are no technological hurdles to the industrial deployment of post-combustion carbon capture. However, the high energy penalty of the process and the associated financial costs hamper the actual use of the technology. Drastically lowering the price of this process is therefore a requisite for the competitiveness of carbon capture as a viable technology to reduce $\mathrm{CO}_{2}$ emissions. $^{1-5}$

${ }^{a}$ Center for Molecular Modeling, Ghent University, B-9052 Zwijnaarde, Belgium. E-mail: veronique. vanspeybroeck@ugent.be

${ }^{b}$ Department of Chemical and Biomolecular Engineering, University of California, Berkeley, CA 94720-1462, USA

'Department of Chemistry, University of California, Berkeley, CA 94720-1462, USA

${ }^{d}$ Laboratory of Molecular Simulation, Institut des Sciences et Ingénierie Chimiques, Valais, Rue d'Industrie 17, Ecole Polytechnique Fédérale de Lausanne (EPFL), CH-1950 Sion, Switzerland. E-mail: berend.smit@epfl.ch $\dagger$ Electronic supplementary information (ESI) available. See DOI: 10.1039/c6fd00031b 
The most mature technology for carbon capture and storage (CCS) to separate $\mathrm{CO}_{2}$ from the post-combustion flue gases is amine scrubbing, a two-step process in which $\mathrm{CO}_{2}$ is first chemically bound to the amines and later recovered in a pure form by 'stripping' the $\mathrm{CO}_{2}$ from the amines at high temperatures. ${ }^{6,7}$ A commonly used amine in this process is monoethanolamine (MEA). Heating the dilute aqueous amine mixture imposes a severe energy penalty on the process. Alternative technologies are therefore proposed, such as adsorption in nanoporous materials. A variety of classes of nanoporous materials exists with high $\mathrm{CO}_{2} / \mathrm{N}_{2}$ selectivity, good $\mathrm{CO}_{2}$ uptake, as well as a less energy demanding regeneration than the amine solutions. ${ }^{\mathbf{8 - 1 0}}$ Among them are metal-organic frameworks (MOFs) ${ }^{11,12}$ zeolitic imidazolate frameworks (ZIFs), ${ }^{13,14}$ porous polymer networks (PPNs), ${ }^{15-17}$ and zeolites. ${ }^{18-21}$

There are several possibilities to lower the cost of post-combustion carbon capture with nanoporous materials, which will be outlined in the following subsections. In the first place, ongoing advances in material research and computational screening methods can help to design a new material with potentially better CCS properties. Secondly, novel ways to operate the carbon capture process can also reduce the energy consumption. Thirdly, changing the operating conditions of the carbon capture process also provides opportunities to save energy. The latter will be the focus of this manuscript.

\subsection{Alternative materials}

Due to rational material synthesis approaches there has been an explosion of new materials in recent years. Since their discovery in the 1990's, some 10000 MetalOrganic Frameworks (MOFs) have been synthesized, and countless new ones as well as specific modifications are designed every year. ${ }^{23}$ Moreover, the importance of zeolites in the petrochemical industry has spurred new developments in the field of zeolite synthesis as well..$^{24,25}$

To compare nanoporous materials among each other, Bae and Snurr presented five criteria to evaluate CCS performance: $\mathrm{CO}_{2}$ uptake, $\mathrm{CO}_{2} / \mathrm{N}_{2}$ selectivity, $\mathrm{CO}_{2}$ working capacity, regenerability of the material and a sorbent selection parameter. ${ }^{26}$ Some of the authors of this manuscript proposed to use one metric instead, the "parasitic energy", i.e. the energy output of the power plant immediately consumed by the CCS process. ${ }^{27,28}$ This metric can easily be related to the industrial application of CCS, as it straightforwardly identifies the material with the lowest energy requirement for CCS.

However, experimentally determining any CCS metric for thousands of possible candidates would be nearly impossible. Therefore, high-throughput computational screenings of databases with existing as well as hypothetical materials have become very attractive tools. They allow us to evaluate millions of materials for their CCS performance and guide experimental efforts in the direction of the most promising materials. With these computer screenings, it is not only possible to assess the boundaries of the material space for their carbon capture performance, but also get molecular insights on the best performing materials. A screening of nanoporous materials from different material families identified that adsorbent-based carbon capture can yield a parasitic energy $30 \%$ lower than that of the amine scrubbing process, but that further improvements are not to be expected..$^{27,28}$ Finally, going beyond brute force computational 
screenings requires machine learning techniques, which have already been applied for gas adsorption in nanoporous materials..$^{12,29,30}$

\subsection{Alternative technologies}

Although the discovery of new materials may gradually improve carbon capture performance, previously mentioned screening studies showed that this approach has its limits. Therefore, it is worth taking a second look at the carbon capture process, shown in Fig. 1. In conventional nanoporous materials-based carbon capture process, the exhaust gases of the power plant are first cooled and $\mathrm{CO}_{2}$ is adsorbed at low temperatures to maximize $\mathrm{CO}_{2}$ uptake. Once the adsorption bed is saturated with $\mathrm{CO}_{2}$, the nanoporous material is regenerated either by heating the material or by applying a vacuum. Either way, a parasitic energy penalty is imposed on the process. Moreover, $\mathrm{H}_{2} \mathrm{O}$ in the exhaust gases will compete for the same adsorption sites as $\mathrm{CO}_{2}$, thereby lowering the $\mathrm{CO}_{2}$ uptake and increasing the parasitic energy. ${ }^{31}$

In the newly proposed "High-temperature Adsorption and Low-temperature Desorption" (HALD) set-up, the temperature-dependent competitive adsorption of $\mathrm{CO}_{2}$ and $\mathrm{H}_{2} \mathrm{O}$ is exploited to overcome the high energy requirement. ${ }^{22,32}$ At high temperatures, the competitive adsorption of $\mathrm{CO}_{2}$ and $\mathrm{H}_{2} \mathrm{O}$ is in favor of $\mathrm{CO}_{2}$, so adsorption at higher temperatures (without first cooling the exhaust gases) improves the selectivity towards $\mathrm{CO}_{2}$. As the competition is in favor of $\mathrm{H}_{2} \mathrm{O}$ at low temperatures, $\mathrm{CO}_{2}$ can be desorbed at low temperatures, by cooling and saturating the absorbent with $\mathrm{H}_{2} \mathrm{O}$. When the regenerated zeolite - void of $\mathrm{CO}_{2}$ but full with $\mathrm{H}_{2} \mathrm{O}$ - is brought into contact again with the hot exhaust gases, the waste energy of the flue gas desorbs the $\mathrm{H}_{2} \mathrm{O}$ from the material and restores the

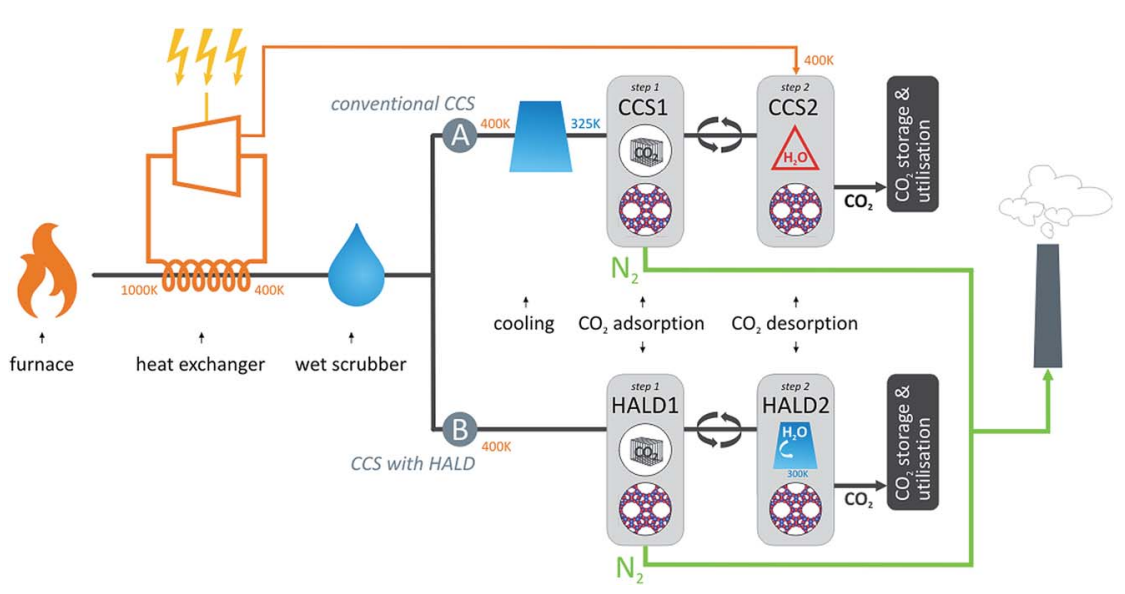

Fig. 1 Layout of a coal-fired power plant. (A) represents a power plant retrofitted with conventional carbon capture technology based on $\mathrm{CO}_{2}$ adsorption on a nanoporous material. The exhaust gases are first cooled and $\mathrm{CO}_{2}$ is subsequently adsorbed. Regeneration of the bed requires a parasitic energy from the power plant, which is even higher when $\mathrm{H}_{2} \mathrm{O}$ is present. (B) is a power plant retrofitted with the proposed High-temperature Adsorption and Low-temperature Desorption (HALD) technology, whereby adsorption takes place at high temperatures and the material is regenerated by cooling the adsorbent while saturating it with $\mathrm{H}_{2} \mathrm{O} .{ }^{22}$ 
competitive advantage of $\mathrm{CO}_{2}$. This temperature swing process utilizes the residual heat of the exhaust gases to overcome the competition with $\mathrm{H}_{2} \mathrm{O}$ and capture the $\mathrm{CO}_{2}$ from this $\mathrm{CO}_{2} / \mathrm{N}_{2} / \mathrm{H}_{2} \mathrm{O}$ mixture and hence does not require the input of energy for regeneration. The upside-down HALD alternative to traditional CCS methods thereby opens new perspectives to reduce the energy penalty of CCS.

\subsection{Alternative operating conditions}

For the application of carbon capture and storage (CCS), the captured $\mathrm{CO}_{2}$ has to be of high purity (99\%) before it can be compressed to a supercritical state at around 150 bar. $^{33}$ Only in these conditions can $\mathrm{CO}_{2}$ efficiently be stored in geological formations. The high purity requirement and the compression to high pressure constitute a large part of the energy penalty for CCS. However, the stringent conditions may not always be necessary for specific cases of carbon capture and utilization (CCU). As a result, the price per tonne $\mathrm{CO}_{2}$ may actually be significantly lower, shifting the economics of $\mathrm{CCU}$ into a more favorable direction.

In Table 1, a few examples of CCU are given. From left to right, the examples are organized with decreasing $\mathrm{CO}_{2}$ purity for the application, $99 \%$, $70 \%$ or $50 \%$. From top to bottom, the $\mathrm{CO}_{2}$ source is indicated: coal-fired power plants, with $14 \% \mathrm{CO}_{2}$ in their flue gases, gas turbine exhaust gases, with about $4 \% \mathrm{CO}_{2}$ flue gases, and air, with $\mathrm{CO}_{2}$ levels of about $400 \mathrm{ppm}$.

An application in which $50 \% \mathrm{CO}_{2}$ could suffice, but for which large amounts of $\mathrm{CO}_{2}$ are needed, is the cultivation of algae for the production of biofuels. ${ }^{34}$ Increased $\mathrm{CO}_{2}$ levels are used to heighten the crop production in greenhouses, although for this application smaller quantities suffice, provided by a gas turbine or a biomass plant for instance. ${ }^{35,36}$ Finally, for the carbonation of drinks, local $\mathrm{CO}_{2}$ production directly from the air could be an option. An interesting example for $70 \% \mathrm{CO}_{2}$ is the production of "Carbstone". ${ }^{37}$ In a chemical process, finely ground $\mathrm{CaO}$ and $\mathrm{MgO}$, waste products from the metallurgical industry, react with $\mathrm{CO}_{2}$ to produce $\mathrm{CaCO}_{3} / \mathrm{MgCO}_{3}$ bricks and tiles. This is an example where $\mathrm{CO}_{2}$ is both permanently sequestered in a chemically stable solid product, as well as utilized for a useful application (CCUS). Smaller amounts of $\mathrm{CO}_{2}$ could be used as an inert gas in welding, ${ }^{38}$ or for specific molding techniques, in which $\mathrm{CO}_{2}$ was found to increase the hardness. ${ }^{39}$ Finally, locally producing small amounts of $\mathrm{CO}_{2}$ could also be practical for fumigation, for instance of bed bugs. ${ }^{40}$ Some cases however do require the use of very pure, $99 \% \mathrm{CO}_{2}$. Enhanced Oil Recovery (EOR) for instance, injects $\mathrm{CO}_{2}$ in near-depleted oil wells under supercritical conditions. ${ }^{41}$ The market for this application is in the order of millions of tonnes of $\mathrm{CO}_{2}$ per year, and therefore large coal-fired power plants are needed to fill that

Table 1 Examples of carbon capture and utilization, organized according to the $\mathrm{CO}_{2}$ content of the $\mathrm{CO}_{2}$ source (in) and the desired $\mathrm{CO}_{2}$ content for the application (out)

\begin{tabular}{llll}
\hline In/out & $99 \%$ & $70 \%$ & $50 \%$ \\
\hline COAL & EOR & Carbstone & Algae \\
NG & Fire extinguisher & Welding/molding & Greenhouses \\
AIR & CCS & Fumigation & Bubbles in drinks
\end{tabular}


demand. For fire extinguishers, pure $\mathrm{CO}_{2}$ is also necessary, but much smaller $\mathrm{CO}_{2}$ sources can be utilized. ${ }^{42}$ Finally, direct air capture could serve as a solution of last resort, when the climate turns really bad and the $\mathrm{CO}_{2}$ level in the atmosphere has to be suppressed on a very short term, direct air capture devices can be used for carbon capture and storage, directly from the atmosphere. ${ }^{\mathbf{4 3 , 4 4}}$

\section{Goal}

The central question in this manuscript is how much the parasitic energy of carbon capture can be lowered by utilizing $\mathrm{CO}_{2}$ at 1 bar and adapting the final purity requirements for $\mathrm{CO}_{2}$ from different $\mathrm{CO}_{2}$ sources. First, we investigate the influence of the final purity requirement for the case of coal-fired power plant flue gases. Then, we extend this analysis to other sources of $\mathrm{CO}_{2}$, the flue gases of natural gas-fired power plants and ambient air. Afterwards, we go into more detail on the purity of the desorbed mixture. Then, the properties of $\mathrm{NaX}$, a commercially available material, and the minimization of the parasitic energy are studied in more detail. Finally, we will compare the calculated CCU cost with reported costs for CCS and available prices for $\mathrm{CO}_{2}$.

\section{Methodology}

The parasitic energy of the carbon capture process stems from the regeneration of the nanoporous material, either by heating the material, by applying a vacuum or a combination of the two. In the first place, the material can be heated up in order to trigger $\mathrm{CO}_{2}$ desorption. This thermal heating energy, $Q_{\text {thermal }}$, not only incorporates the sensible heat requirement to heat the material but also the required desorption heat of $\mathrm{CO}_{2}$. The latter heat term is required to undo the binding of the $\mathrm{CO}_{2}$ to the nanoporous material in order to proceed with the storage process. Accordingly, the thermal energy requirement per mass $\mathrm{CO}_{2}$ is given by:

$$
Q_{\text {thermal }}=\frac{C_{\mathrm{p}} m_{\text {sorbent }} \Delta T}{m_{\mathrm{CO}_{2}}}+\frac{\Delta h_{\mathrm{CO}_{2}} \Delta \sigma_{\mathrm{CO}_{2}}+\Delta h_{\mathrm{N}_{2}} \Delta \sigma_{\mathrm{N}_{2}}}{m_{\mathrm{CO}_{2}}},
$$

with the first term representing the sensible heat, which includes the parameters of the specific heat capacity $C_{\mathrm{p}}$ of the nanoporous material, the mass of the adsorbent $m_{\text {sorbent }}$, and the temperature difference between the adsorption and desorption process $\Delta T$. The second term corresponds to the desorption heat, which is characterized by the working capacities $\Delta \sigma_{\mathrm{i}}$ and the heat of adsorption $\Delta h_{\mathrm{i}}$ for both components, respectively. Pure component $\mathrm{CO}_{2}$ and $\mathrm{N}_{2}$ isotherms are obtained by fitting Langmuir isotherms to experimental data, if available, or data from molecular simulations. Moreover, Ideal Adsorbed Solution Theory (IAST), ${ }^{45}$ is used to predict the behavior of a $\mathrm{CO}_{2} / \mathrm{N}_{2}$ gas mixture.

The second contribution to the parasitic energy is related to the compression of the desorbed $\mathrm{CO}_{2}$ to either 1 bar, for utilization, or to $150 \mathrm{bar}$, for transportation and storage. The compression energy is mainly determined by the $\mathrm{CO}_{2}$ purity and the desorption pressure. The pumping work, $W_{\text {comp }}$, is estimated by means of the NIST REFPROP database ${ }^{46}$ and a linear regression based on this data. The isentropic efficiency of the pump is assumed to be $85 \%$ for gas below the supercritical point and $90 \%$ above it. 
For the overall parasitic energy, we assume that heat is delivered by steam from the power plant and that the compressors are driven by the produced electricity directly. To calculate the total parasitic energy, the loss in the power plant's production, the compression work can be used directly, whereas for the heat, a typical turbine efficiency of $75 \%^{47}$ and the Carnot efficiency $\eta$ to convert thermal energy into electrical work have to be taken into account to translate the heat loss in an output loss:

$$
E_{\text {parasitic }}=\left(0.75 Q_{\text {thermal }} \eta_{\text {Carnot }}\right)+W_{\text {comp }} \text {. }
$$

This total energy requirement can be minimized by varying the final operation conditions of the desorption process, i.e. temperature and/or pressure. These desorption processes are referred to as Temperature-Pressure Swing Adsorption (TPSA), Temperature Swing Adsorption (TSA) or Pressure Swing Adsorption (PSA), depending which parameters are varied or fixed, in each case. TPSA operates at changing temperature and pressure, whereas TSA is characterized by constant pressure (set to $p_{\text {des }}=1 \mathrm{~atm}$; this equals adsorption pressure) and PSA features a fixed temperature $\left(T_{\mathrm{des}}=333 \mathrm{~K}\right)$. The considered desorption conditions range from $0.01 \mathrm{~atm}<p_{\mathrm{des}}<3 \mathrm{~atm}$ and $333 \mathrm{~K}<T_{\mathrm{des}}<473 \mathrm{~K}$ for pressure and temperature, respectively.

The database includes five classes of nanoporous materials, which are partially of hypothetical nature. These comprise metal-organic frameworks (MOFs), ${ }^{48-61}$ zeolitic imidazolate frameworks (ZIFs) ${ }^{62-64}$ porous polymer networks (PPNs), ${ }^{65}$ zeolites $^{20}$ and cation exchanged zeolites (CEZs). ${ }^{18}$ Moreover, two classes of hypothetical materials are considered: HMOFs - analogs of the well-studied MOF-5 (ref. 66) - and hypothetical ZIF structures. The class of CEZs is represented by Linde type A and type X zeolites where the Na-cations are partially exchanged by the alkaline earth metals magnesium and calcium. Alongside the fully coordinated MOFs, UMCM- 1 and MOF177, we also included MOFs with open metal sites, like the series M-MOF-74, CuBTC, and CuBTTri. ${ }^{11,26,67-69}$ Of special interest in recent years are also porous polymer networks (PPNs) tethered with different polyamines. ${ }^{\text {70,71 }}$

A full description of the methodology, the assumptions and the considered materials can be found in ref. 28 .

\section{Results \& discussion}

\subsection{Minimum energy}

Before we dig deeper into the performance of the different materials, it is worth looking at this problem from an elementary thermodynamical viewpoint. ${ }^{72,73}$ It is possible to calculate the minimum work to separate $\mathrm{CO}_{2}$ from a two-component gas mixture, $W_{\mathrm{min}}^{\mathrm{sep}}$, using the molar entropy of an ideal gas mixture containing a mole fraction $x$ of $\mathrm{CO}_{2}$, according to

$$
\begin{gathered}
s^{\mathrm{im}}(x)=-R[x \ln x+(1-x) \ln (1-x)] \\
-W_{\mathrm{min}}^{\mathrm{sep}}=-T_{\mathrm{sep}}\left[n_{\mathrm{em}} s^{\mathrm{im}}\left(x_{\mathrm{em}}\right)+n_{\mathrm{cap}} s^{\mathrm{im}}\left(x_{\text {cap }}\right)-n_{\text {flue }} s^{\mathrm{im}}\left(x_{\text {flue }}\right)\right],
\end{gathered}
$$

where $n_{\text {em }}, n_{\text {cap }}$ and $n_{\text {flue }}$ are the number of moles of the emitted, captured and flue gas, respectively. A more detailed description of the calculation is given in the 
ESI. $\dagger$ Fig. 2 shows the minimum separation energy landscape for a range of initial compositions ( $x_{\text {flue }}$ on the $y$-axis) and final compositions ( $x_{\text {cap }}$ on the $x$-axis) at 313 $\mathrm{K}$. Note that the temperature of the flue gases is set to $313 \mathrm{~K}$, whereas the ambient air is assumed to be $288 \mathrm{~K}$. In this work, we focus on three sources of $\mathrm{CO}_{2}$ : coalfired power plants, with $14 \% \mathrm{CO}_{2}$ in their flue gases, natural gas-fired power plants, emitting $4 \% \mathrm{CO}_{2}$, and ambient air, with some $400 \mathrm{ppm}$ of $\mathrm{CO}_{2}(0.04 \%)$. Moreover, we will consider three final purity requirements, $99 \%, 70 \%$ and $50 \%$ $\mathrm{CO}_{2}$. These distinct compositions are shown in Fig. 2 on top of the minimum separation energy landscape. Moreover, Table 2 shows numerical values for the minimum energy requirement across the compositions we will investigate in this manuscript.

Direct air capture is situated in a very unfavorable region of this energy landscape and relative improvements are relatively small. For coal on the other hand, almost $50 \%$ minimum energy can be saved by lowering the purity of the final mixture from $99 \%$ to $50 \%$. The energy requirement for upgrading the natural gas flue gas from $4 \%$ to $50 \%$ is almost identical to upgrading coal flue gas from $14 \%$ to $99 \%$. This observation already opens perspectives to lower the cost of carbon capture from natural-gas fired power plants, given that applications for $\mathrm{CO}_{2}$ at $50 \%$ purity can be found.

\subsection{Influence of the purity requirement}

Now, let us return to the selection of 62 nanoporous materials to consider carbon capture from the flue gas of coal-fired power plants. This flue gas has the highest $\mathrm{CO}_{2}$ content and is therefore the most practical $\mathrm{CO}_{2}$ source for post-combustion

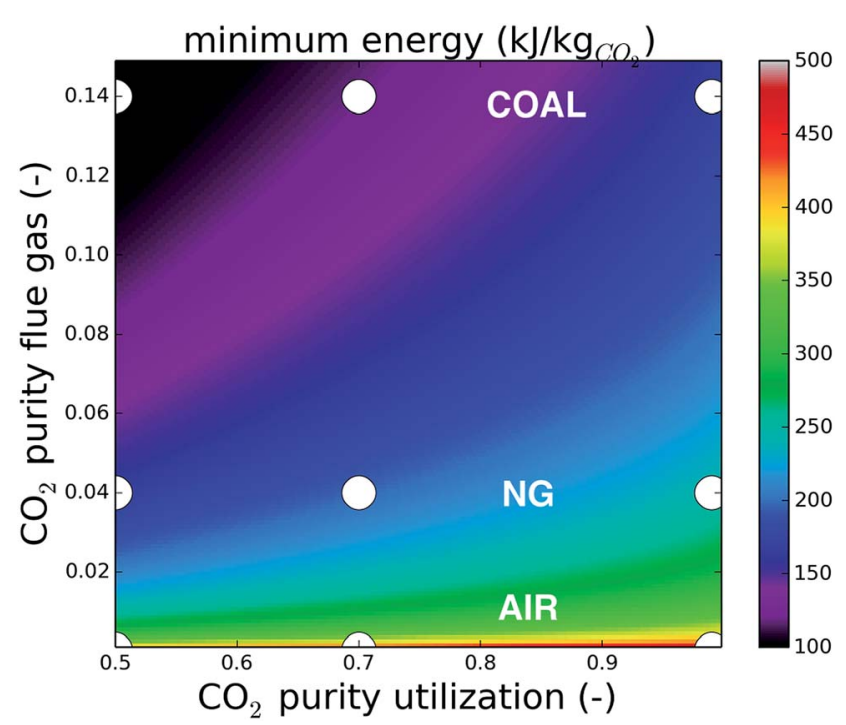

Fig. 2 The minimum energy (in $\mathrm{kJ} \mathrm{kgCO}_{2}{ }^{-1}$ ) to separate $\mathrm{CO}_{2}$ from a binary mixture with an initial content ( $y$-axis) to a final composition ( $x$-axis), at $313 \mathrm{~K}$ and 1 bar. The points relevant in this manuscript are shown in white. The adsorption temperature in the case of direct air capture is $288 \mathrm{~K}$ in this manuscript, which lowers the minimum energy compared to the values in this figure. 
Table 2 The minimum energy (in $\mathrm{kJ} \mathrm{kgCO}_{2}{ }^{-1}$ ) to separate $\mathrm{CO}_{2}$ from a carbon source into a final composition. For coal (COAL) and natural gas (NG) flue gas, the temperature is set at $313 \mathrm{~K}$, for direct air capture (AIR) at $288 \mathrm{~K}$. The final pressure is set to 1 bar

Final composition

\begin{tabular}{lllll}
$\mathrm{CO}_{2}$ source & $99 \%$ & $70 \%$ & $50 \%$ \\
\hline $\mathrm{COAL}$ & $14 \%$ & 168 & 119 & 89 \\
$\mathrm{NG}$ & $4 \%$ & 245 & 197 & 166 \\
$\mathrm{AIR}$ & $0.04 \%$ & 477 & 432 & 404
\end{tabular}

carbon capture. Fig. 3 shows the parasitic energy to capture $\mathrm{CO}_{2}$ from coal flue gas as a function of the $\mathrm{CO}_{2}$ Henry coefficient $\left(k_{\mathrm{H}, \mathrm{CO}_{2}}\right)$ at $300 \mathrm{~K}$, for the original requirement of CCS, with $\mathrm{CO}_{2}$ at $99 \%$ purity and compressed to 150 bar and for the cases of $99 \%, 70 \%$ and $50 \%$ purity at 1 bar. First of all, the compression work from 1 to 150 bar comprises a large part of the parasitic energy and is hence an important part of the cost for CCS. Fig. S1 in the ESI $\dagger$ shows that this contribution to the parasitic energy exceeds $55 \%$, especially for the best performing materials. Furthermore, lowering the purity requirement from $99 \%$ down to 70 or $50 \%$ further reduces the parasitic energy, although the relative improvements are much smaller than the parasitic energy reduction when omitting the 1 to $150 \mathrm{bar}$ compression work.

The parasitic energy of the amine technology with monoethanolamine (MEA), $1065 \mathrm{~kJ} \mathrm{~kg}_{\mathrm{CO}_{2}}{ }^{-1}$, is indicated with a solid line. Please note that for the MEA technology, the $353 \mathrm{~kJ} \mathrm{~kg}_{\mathrm{CO}_{2}}{ }^{-1}$ compression work from 1 bar to 150 bar can be avoided, leaving the heating energy as the only contribution to the parasitic

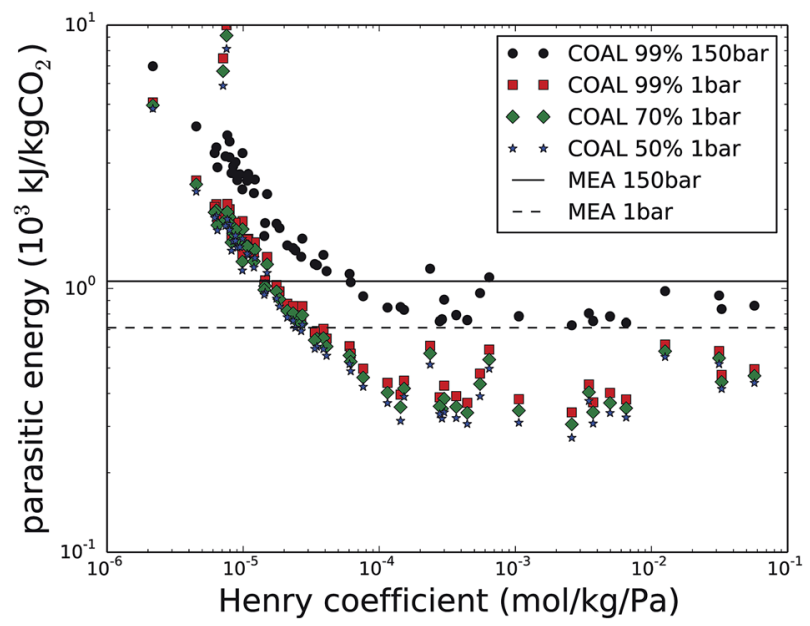

Fig. 3 The parasitic energy to capture $\mathrm{CO}_{2}$ from coal flue gas as a function of the $\mathrm{CO}_{2}$ Henry coefficient $\left(\mathrm{K}_{\mathrm{H}, \mathrm{CO}_{2}}\right)$ at $300 \mathrm{~K}$. The original parasitic energy is given in black, with $\mathrm{CO}_{2}$ at $99 \%$ purity and compressed to 150 bar. The cases for $99 \%, 70 \%$ and $50 \%$ purity at 1 bar are shown in red, green and blue respectively. Current MEA technology is marked as a solid line whereas the heating requirement of the MEA technology (excluding the compression from 1 to 150 bar) is shown as the dashed line. 
energy (indicated with a dashed line in Fig. 3). This corresponds to $712 \mathrm{~kJ} \mathrm{~kg}_{\mathrm{CO}_{2}}{ }^{-1}$, $33 \%$ lower than the original case. The purity of the final mixture however cannot be altered for MEA, as only $\mathrm{CO}_{2}$ reacts with the amines and is therefore recovered at $100 \%$. Within the scope of lowering the energy requirement of carbon capture for certain cases, of carbon utilization, solid adsorbents therefore provide larger margins for energy improvements than amines.

Table 3 shows the parasitic energy of the best performing materials for carbon capture from coal-fired power plants, for different final requirements. Mg-MOF-74 is the best candidate regardless of the final purity requirement. Not compressing the $\mathrm{CO}_{2}$ to 150 bar saves $388 \mathrm{~kJ} \mathrm{~kg}_{\mathrm{CO}_{2}}{ }^{-1}$ and lowers the parasitic energy with $54 \%$. The net compression work is slightly higher than for MEA, as the $\mathrm{CO}_{2}$ is not $100 \%$ pure when using Mg-MOF-74, so some $\mathrm{N}_{2}$ has to be compressed as well. Further lowering the purity requirement decreases the parasitic energy from 339 to $271 \mathrm{~kJ}$ $\mathrm{kg}_{\mathrm{CO}_{2}}{ }^{-1}$, an additional improvement of $20 \%$. This is however much lower than the contribution of the 1-150 bar compression work.

The order of the other top-performing materials shifts slightly, depending on the imposed final conditions. The polyamine-tethered porous polymer network PPN-6- $\mathrm{CH}_{2}-\mathrm{TETA}^{74}$ disappears from the selection at $70 \%$ and $50 \%$. The same is true for the amine-functionalized metal-organic framework mmen-CuBTTri. Finally, for all considered cation-exchanged X-type zeolite $(\mathrm{Mg}, \mathrm{Na}, \mathrm{Ca})$, the parasitic energy is very similar across the considered cases. The cation-exchanged zeolites are of high interest, as they combine their good carbon capture properties with commercial availability on the tonne scale. This is especially true for zeolite $\mathrm{NaX}$, which is often used as a reference material for solid-adsorbent carbon capture. $^{31,75-77}$ Finally, as the difference in carbon capture performance between the readily available $\mathrm{NaX}$, and the yet-to-be commercialized Mg-MOF-74 is small, there is no reason to wait for the industrial production of novel materials in order to do carbon capture with solid adsorbents.

\subsection{Influence of the carbon source}

Extending the analysis to other sources of $\mathrm{CO}_{2}$, such as the flue gas of natural gasfired power plants (with typically $4 \% \mathrm{CO}_{2}$ content) and ambient air (with $\mathrm{CO}_{2}$ levels of $400 \mathrm{ppm}$ ), yields Fig. $4 \mathrm{a}$. The 1-150 bar compression work is omitted in all cases and focus is on the imposed final purity. Fig. $4 \mathrm{~b}$ shows the relative improvement between the parasitic energy for $50 \%$ versus $99 \%$ imposed purity for coal flue gases, natural gas flue gases and ambient air.

Table 3 Parasitic energy $\left({\mathrm{KJ} \mathrm{kg} \mathrm{CO}_{2}}^{-1}\right)$ of the five best performing materials for carbon capture from the flue gas of coal-fired power plants (COAL), for different final conditions

COAL

\begin{tabular}{llllllll}
\hline 150 bar, 99\% & & 1 bar, 99\% & & 1 bar, 70\% & \multicolumn{3}{c}{ 1 bar, 50\% } \\
\hline Mg-MOF-74 & 727 & Mg-MOF-74 & 339 & Mg-MOF-74 & 305 & Mg-MOF-74 & 271 \\
PPN-6-CH - -TETA & 742 & MgX & 369 & MgX & 338 & MgX & 306 \\
mmen-CuBTTri & 752 & NaX & 370 & NaX & 340 & NaX & 308 \\
NaX & 754 & PPN-6-CH - TETA & 380 & CaX & 344 & CaX & 310 \\
MgX & 760 & CaX & 381 & NaA & 350 & Zn-MOF-74 & 315
\end{tabular}


As expected from the minimum energy calculations in Table 2, the parasitic energy for direct air capture is higher than that for carbon capture from natural gas flue gases or coal flue gases. Moreover, throughout the carbon sources, lower final purity requirements decrease the parasitic energy. The largest gains are found for direct air capture, for which a lot of the poorly performing materials exhibit relative improvements of $20-60 \%$ between $99 \%$ and $50 \%$ purity. This observation does not correspond to the conclusions from the minimum energy calculations, which predicted much lower improvements for direct air capture. Therefore, these large improvements are likely related to improvements in the process, rather than in the thermodynamics of air capture. For coal and natural gas, $10-20 \%$ energy can typically be saved, especially for the best performing materials.
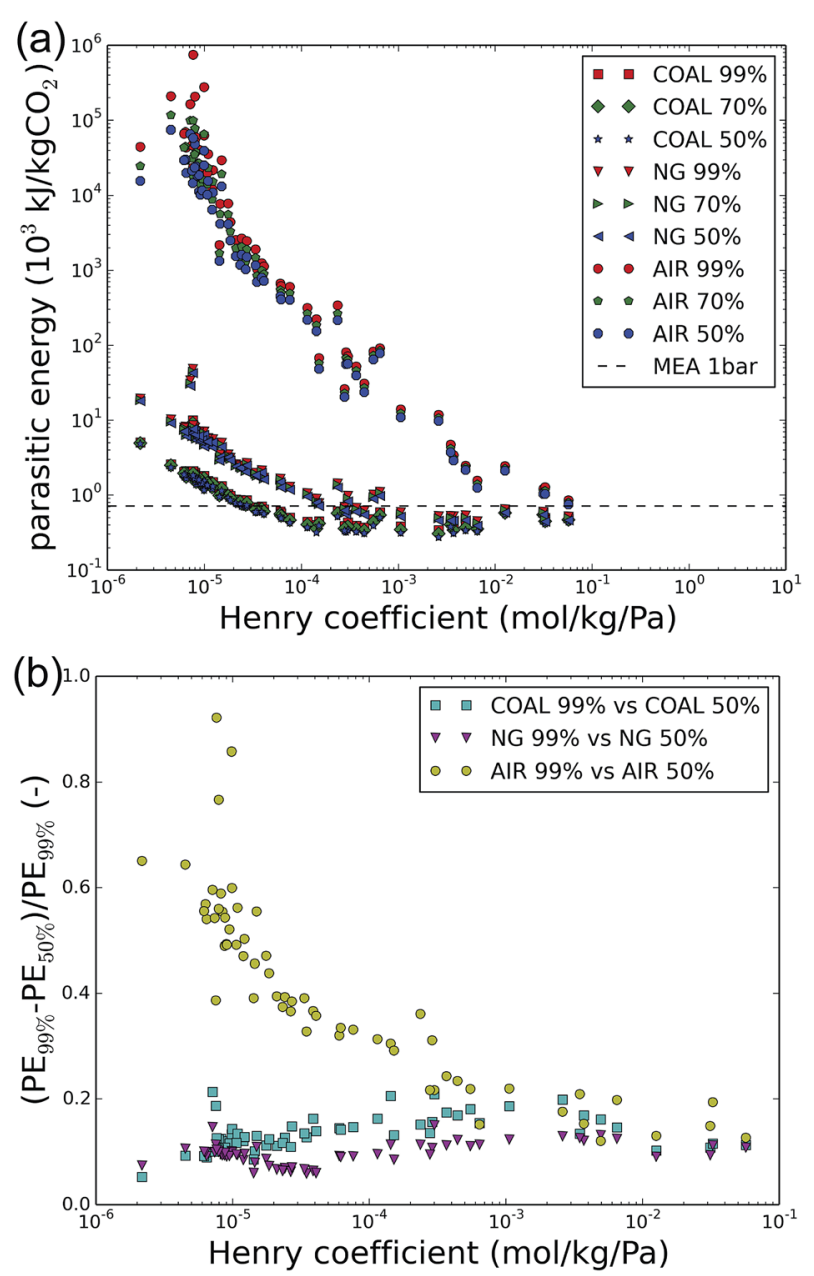

Fig. 4 (a) The parasitic energy to capture $\mathrm{CO}_{2}$ from a coal-fired power plant (COAL), a natural gas-fired power plant (NG) or directly from air (AIR). Final purity requirements of 50,70 and $99 \%$ are shown and 1 bar is maintained across all cases. (b) The relative gain in parasitic energy (PE) between the parasitic energy for $50 \%$ versus $99 \%$ imposed purity for coal flue gases, natural gas flue gases and ambient air. 
Table 4 lists the five best performing materials for carbon capture from the flue gas of natural gas-fired power plants and directly from air, for the different final requirements. For natural gas flue gases, the functionalized PPN-6 materials have the lowest parasitic energy requirements. The top performer is polyamine-tethered porous polymer network PPN-6- $\mathrm{CH}_{2}$-TETA, which was already mentioned among the five best candidates for carbon capture from coal flue gases. The metal-organic material (MOM) zinc hexafluorosilicate $\left(\mathrm{SiF}_{6}{ }^{-2}\right)$, SIFSIX-3-Zn, is highly selective for $\mathrm{CO}_{2} \cdot{ }^{78,79}$ In cases of lower purity, Mg-MOF-74 again acts as a promising candidate. And finally, the commercially available zeolite $\mathrm{NaX}$ is present in the top-5 materials for all purities. As opposed to the case of coal flue gases however, its performance is drastically lower than its competitors. For $\mathrm{CO}_{2}$ capture at $99 \%$ purity and 150 bar, $\mathrm{NaX}$ has a parasitic energy of $925 \mathrm{~kJ} \mathrm{~kg}_{\mathrm{CO}_{2}}{ }^{-1}$ whereas for PPN-6-CH$-\mathrm{CH}_{2}$-TETA, this is only $807 \mathrm{~kJ} \mathrm{~kg}_{\mathrm{CO}_{2}}{ }^{-1}$.

For $\mathrm{CO}_{2}$ capture directly from air, again the functionalized PPN-6 materials are suitable candidates, with $\mathrm{PPN}-6-\mathrm{CH}_{2}$-DETA as the material with the lowest parasitic energy. The differences in parasitic energy, even among the five best performers, are much larger than in the case for capture from coal or natural gas flue gases. Due to this wider spacing, the relative order of the materials does not change with changing purity requirements. Copper hexafluorosilicate $\left(\mathrm{SiF}_{6}{ }^{-2}\right)$, SIFSIX-3-Cu, is the second best material. And the zeolitic imidazolate framework ZIF-36-CAG also appears in this list. NaX is in the seventh place, with a parasitic energy of almost four times that of PPN-6- $\mathrm{CH}_{2}$-DETA (e.g. 2889 $\mathrm{kJ} \mathrm{kg}_{\mathrm{CO}_{2}}{ }^{-1}$ for NaX versus $746 \mathrm{~kJ} \mathrm{~kg}_{\mathrm{CO}_{2}}{ }^{-1}$ for PPN-6-CH - -DETA in the case of $50 \%$ pure $\mathrm{CO}_{2}$ ).

In Table 5, the parasitic energies of the best performing materials for each source of $\mathrm{CO}_{2}$ are compared across the imposed purities. From Tables 3 and 4, we concluded that for $\mathrm{CO}_{2}$ capture from coal-fired power plants, Mg-MOF-74 had the optimal properties, for natural gas-fired power plants, this was PPN-6- $\mathrm{CH}_{2}$-TETA and for direct air capture $\mathrm{PPN}-6-\mathrm{CH}_{2}$-DETA. Lowering the final purity requirement

Table 4 Parasitic energy $\left({\mathrm{kJ} \mathrm{kgCO}_{2}}^{-1}\right)$ of the five best performing materials for carbon capture from the flue gas of natural gas-fired power plants (NG) and directly from air (AIR), for different final conditions

\begin{tabular}{|c|c|c|c|}
\hline 150 bar, 99\% & 1 bar, 99\% & 1 bar, $70 \%$ & $1 \mathrm{bar}, 50 \%$ \\
\hline \multicolumn{4}{|l|}{ NG } \\
\hline PPN6-CH ${ }_{2}$-TETA 807 & PPN6-CH ${ }_{2}$-TETA 444 & PPN6-CH ${ }_{2}$-TETA 416 & PPN6-CH ${ }_{2}$-TETA 389 \\
\hline PPN6-CH ${ }_{2}$-TAEA 858 & PPN6-CH ${ }_{2}$-TAEA 494 & PPN6-CH ${ }_{2}$-TAEA 466 & PPN6-CH ${ }_{2}$-TAEA 439 \\
\hline PPN6-CH ${ }_{2}$-DETA 880 & PPN6-CH ${ }_{2}$-DETA 515 & Mg-MOF-74 486 & Mg-MOF-74 454 \\
\hline SIFSIX-3-Zn $\quad 907$ & NaX $\quad 518$ & PPN6-CH ${ }_{2}$-DETA 487 & SIFSIX-3-Zn \\
\hline $\mathrm{NaX}$ & SIFSIX-3-Zn & NaX 488 & $\mathrm{NaX}$ \\
\hline
\end{tabular}

\section{AIR}

PPN6-CH ${ }_{2}$-DETA 1215 PPN6-CH $-\mathrm{CH}_{2}$-DETA 854 PPN6-CH $-\mathrm{CH}_{2}$-DETA 797 PPN6-CH 2 -DETA 746 SIFSIX-3-Cu 1617 SIFSIX-3-Cu 1206 SIFSIX-3-Cu 1112 SIFSIX-3-Cu 1026 PPN6-CH ${ }_{2}$-TAEA 1645 PPN6- $\mathrm{CH}_{2}$-TAEA 1281 PPN6-CH - -TAEA 1145 PPN6-CH ${ }_{2}$-TAEA 1033 PPN6-CH ${ }_{2}$-TETA 1948 PPN6- $\mathrm{CH}_{2}$-TETA 1564 PPN6-CH - -TETA 1398 PPN6-CH PETA $_{2} 1254$ ZIF-36-CAG 3240 ZIF-36-CAG 2439 ZIF-36-CAG 2248 ZIF-36-CAG 2122 
from $99 \%$ to $50 \%$ lowers the parasitic energy with almost $20 \%$ for Mg-MOF-74, whereas for PPN-6-CH - -TETA and PPN-6-CH$-\mathrm{CH}_{2}$-DETA, the possible improvement is only $12 \%$. Interestingly, for direct air capture, the parasitic energy requirement when purifying $\mathrm{CO}_{2}$ from $400 \mathrm{ppm}$ to $50 \%\left(746 \mathrm{~kJ} \mathrm{~kg}_{\mathrm{CO}_{2}}{ }^{-1}\right)$ is only marginally higher than the original parasitic energy requirement for $\mathrm{CO}_{2}$ at 150 bar and $99 \%$ purity from coal flue gas $\left(727 \mathrm{~kJ} \mathrm{~kg}_{\mathrm{CO}_{2}}{ }^{-1}\right)$. This indicates that direct air capture could be an attractive method to win $\mathrm{CO}_{2}$ for specific cases of carbon utilization.

\subsection{Importance of the final purity}

In the previous sections, the $\mathrm{CO}_{2}$ purity was a key factor in the discussion. The initial purity of $\mathrm{CO}_{2}$ is determined by the composition of the flue gas or the air, and is therefore fixed by the carbon source. For the final purity of $\mathrm{CO}_{2}$, we assumed that this is imposed by the operation of the carbon capture process. However, Fig. 5 reveals that this is not necessarily the case. In this plot, the results from Fig. 3 are color coded based on the final purity, after optimization of the parasitic energy. For a coal-fired power plant flue gas and with final purities set to $99 \%, 70 \%$ and $50 \%$, only the best performing materials actually attain purities higher than $90 \%$. Moreover, even when the purity requirement is gradually lowered (circles, squares and triangles at the same Henry coefficient), this barely influences the final purity. This indicates that the final purity of the recovered gas mixture is in fact imposed by the material properties (e.g. Henry coefficient), rather than by the operating conditions.

Fig. 6 shows the final purity as a function of the $\mathrm{CO}_{2} / \mathrm{N}_{2}$ selectivity of the material at adsorption conditions. A correlation exists between the $\mathrm{CO}_{2}$ selectivity, a material property, and the final $\mathrm{CO}_{2}$ purity, an outcome of the carbon capture process optimization. For coal flue gases, there is no significant difference between the different cases of imposed purity, which is a process parameter. Fig. S2 and S3 in the ESI $\uparrow$ show that the points for natural gas flue gases and direct air capture are slightly further apart. In any case, the $\mathrm{CO}_{2} / \mathrm{N}_{2}$ selectivity of the used material influences the final purity more than the imposed purity does.

Moreover, a couple of interesting correlations with the purity are shown in Fig. 7. For clarity, the points are limited to the flue gases of coal-fired power plants. In the ESI, $\uparrow$ the correlations are also given for natural gas flue gases and air. In Fig. 7a, the parasitic energy is plotted as a function of the final purity. Generally, the parasitic energy of a material decreases with increasing final purity. At very high final purity (>95\%) however, the parasitic energies increase again, suggesting that the last percents are the most difficult to obtain. As was already clear from previous plots, the imposed purity also has an influence on the

Table 5 The parasitic energies of the best performing materials for each source of $\mathrm{CO}_{2}$ are compared across the imposed final pressures and purities

\begin{tabular}{lllll}
\hline & $\begin{array}{l}150 \text { bar, } \\
99 \%\end{array}$ & 1 bar, 99\% & 1 bar, 70\% & 1 bar, 50\% \\
\hline COAL & 727 & 339 & 305 & 271 \\
NG & 807 & 444 & 416 & 389 \\
AIR & 1215 & 854 & 797 & 746
\end{tabular}




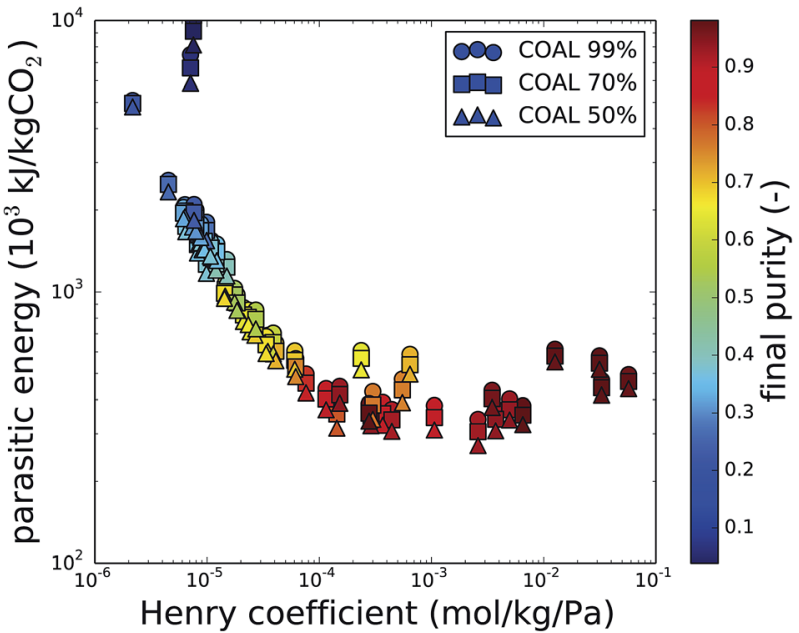

Fig. 5 The parasitic energy to capture $\mathrm{CO}_{2}$ from coal flue gas as a function of the $\mathrm{CO}_{2}$ Henry coefficient $\left(k_{\mathrm{H}, \mathrm{CO}_{2}}\right)$ at $300 \mathrm{~K}$, for $\mathrm{CO}_{2}$ at $99 \%, 70 \%$ or $50 \%$ and 1 bar. The color code indicates the purity of the final gas mixture and shows that the purity requirement of $99 \%$ is only obtained for the best performing materials.

parasitic energy. For air capture (See Fig. S4 in the ESI†), most materials fail to meet the purity requirements, and hence result in parasitic energies of up to 4 orders of magnitude higher. Fig. $7 \mathrm{~b}$ reveals an even clearer correlation between the final purity and the compression energy. Also here, both the imposed and the final purity have an effect on the compression energy. Therefore, it pays off to use a highly selective $\mathrm{CO}_{2}$ adsorbent and lower the purity requirements later, rather

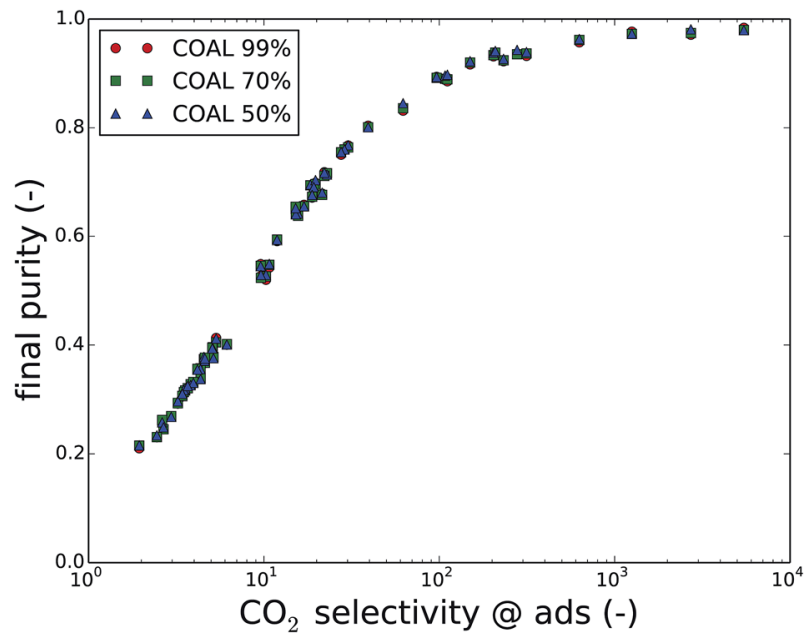

Fig. 6 The final purity as a function of the $\mathrm{CO}_{2} / \mathrm{N}_{2}$ selectivity of the material at adsorption conditions for carbon capture from coal flue gases at different imposed purities $(99 \%, 70 \%$, $50 \%$ ). Note that the selectivity is a material property, the imposed purity an adaptable process parameter and the final purity an outcome of the process optimization. 

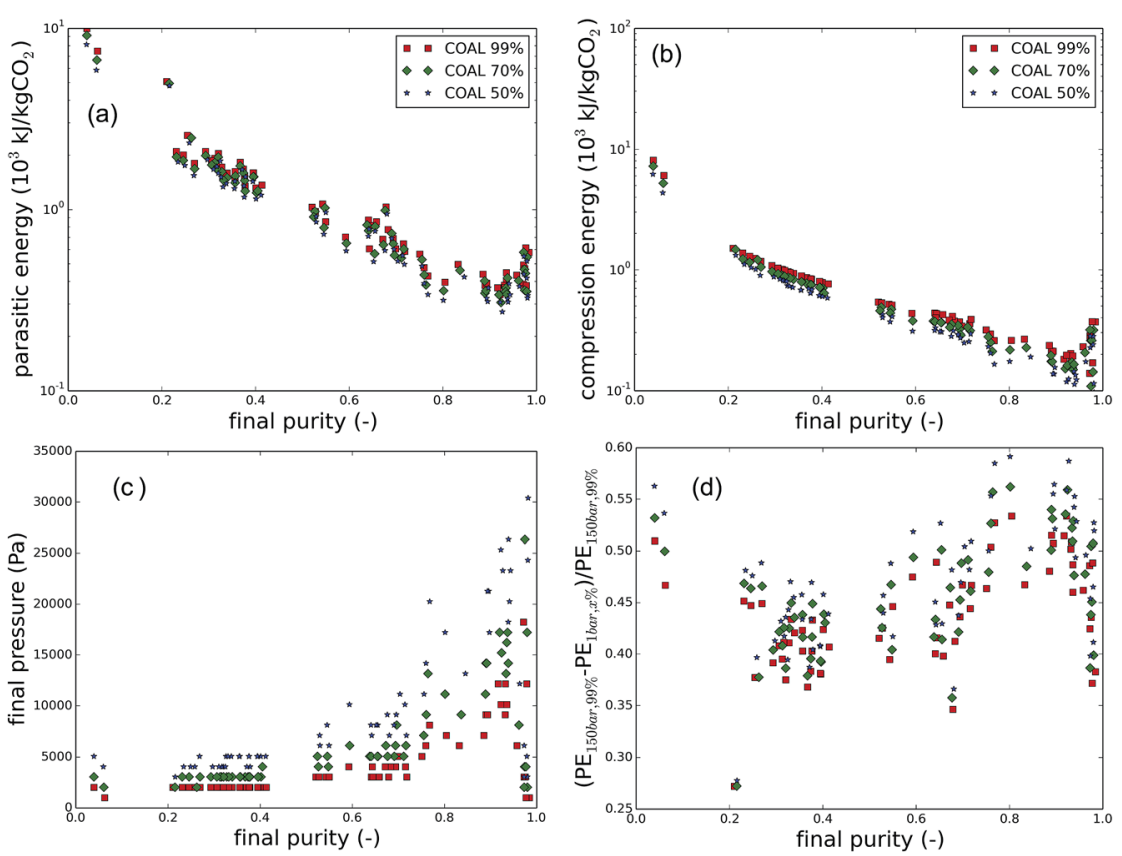

Fig. 7 (a) Parasitic energy as a function of the final purity, (b) the compression part of the parasitic energy as a function of the final purity, (c) the final pressure as a function of the final purity, (d) improvement of the parasitic energy, compared to the reference case of $\mathrm{CO}_{2}$ at 150 bar and $99 \%$ imposed purity, all as a function of the final purity.

than using a less selective material $\mathrm{CO}_{2}$ which would meet the goals. This is due to the compression work of the additional $\mathrm{N}_{2}$ in the capture gas stream, as can be explained by Fig. 7c. The pressure at which $\mathrm{CO}_{2}$ is recovered varies the most at high purity, dropping significantly across the imposed final purity, whereas at low purity, there is almost no improvement possible. Finally, in Fig. 7d, the parasitic energy across the different cases is compared with the original parasitic energy requirement for $\mathrm{CO}_{2}$ at $99 \%$ and 150 bar shows that improvements of almost $60 \%$ are possible, especially when using coal flue gases as the carbon source. For direct air capture, the possible improvement of most materials is very low, but there are also some promising outliers at high purity (see Fig. S4 in ESI $\dagger$ ).

These plots demonstrate that on the one hand, for one specific material, the parasitic energy is reduced when lower purity requirements are imposed. On the other hand, across the different materials, the trend is that the higher the purity of the final mixture, the lower the parasitic energy requirement. Although the purity is mainly imposed by the $\mathrm{CO}_{2} / \mathrm{N}_{2}$ selectivity of the material, which is fixed, there is some margin to tune the desorption pressure in order to lower the compression work of the regeneration. Therefore, the best strategy is to choose a highly selective material, which will hence yield a high final purity, ensuring a low parasitic energy among competing materials. Subsequently, the carbon capture process can be operated at a lower imposed purity, thereby reducing the parasitic energy. 
Finally, when the desired purity is not met, a second adsorption step can be introduced. This step will be less energy-demanding, but will increase the parasitic energy of the overall process. This is an interesting extension for future work.

\subsection{Case study: zeolite NaX}

Zeolites are the work horses of the petrochemical industry, with widespread uses in catalysis and adsorption. Moreover, they have excellent regenerability and high stability in a wide range of environments. The commercial availability of zeolite $\mathrm{NaX}$ (or 13X) in particular, is truly unique among the considered materials. ${ }^{80}$ Only a handful of MOFs have been commercialized so far, with prices that are many times that of zeolites. ${ }^{81}$ The other materials discussed in this manuscript are even further away from industrial applications.

Fig. 8 shows the Langmuir isotherms of $\mathrm{CO}_{2}$ and $\mathrm{N}_{2}$ in $\mathrm{NaX}$, for carbon capture from coal flue gases (a) and directly from air (b) respectively. The numerical values for the desorption pressure, temperature and purity, as well as the compression, heating and parasitic energy are given in Table 6. For coal flue gases, the $\mathrm{CO}_{2}$ loading during adsorption conditions is high among its competitors: almost 150 $\mathrm{g}_{\mathrm{CO}_{2}} \mathrm{~kg}_{\mathrm{Nax}}{ }^{-1}$, as is its selectivity $\left(\mathrm{CO}_{2} / \mathrm{N}_{2}\right)$ with 314 , resulting in a relatively low $\mathrm{N}_{2}$ uptake. Optimizing the parasitic energy includes a trade-off between pulling a stronger vacuum, and hence evacuating more $\mathrm{CO}_{2}$ from the material in one step, and keeping a higher desorption pressure, but requiring more energy for heating the material. The result of this optimization is the ideal amount of $\mathrm{CO}_{2}$ recovered in one step, the difference in the $\mathrm{CO}_{2}$ loading at adsorption and the $\mathrm{CO}_{2}$ loading at desorption. This amount remains more or less constant across the imposed final purities. Lowering the final purity requirement means that the desorption sweep stream contains less $\mathrm{CO}_{2}$ and that therefore, the driving force for $\mathrm{CO}_{2}$ to leave the framework increases. As a result, the desorption isotherm moves towards higher total pressures, and hence, lower pressures are needed to evacuate the same amount of $\mathrm{CO}_{2}$.

For direct air capture, Fig. 8b, the performance of NaX is suboptimal. In this case, the desorption pressure reached the lower limit of $1013 \mathrm{~Pa}$ for all cases. Therefore, the temperature has to be increased in order to recover enough $\mathrm{CO}_{2}$. However, the $\mathrm{CO}_{2}$ working capacity is still poor (only $20 \%$ of that for coal flue gases) and the final purity is below any of the imposed purities (around 34\%). It is however possible to imagine carbon utilization at $30 \%$, for instance to improve crop growth in greenhouses. ${ }^{35,36}$

\section{Cost from a sequestration and utilization viewpoint}

As for any other chemical compound, there is a market for $\mathrm{CO}_{2}$. As opposed to any other market however, the $\mathrm{CO}_{2}$ supply however exceeds its demand with several orders of magnitude, as illustrated in Table 7. On the supply side, the 36 billion metric tons of $\mathrm{CO}_{2}$ emitted in 2015. On the demand side, some 80 million metric tons of $\mathrm{CO}_{2}$, most of which were used for Enhanced Oil Recovery (EOR). Currently, the $\mathrm{CO}_{2}$ used for EOR is delivered from natural $\mathrm{CO}_{2}$ reservoirs, rather than from carbon capture in power plants. ${ }^{82}$ Moreover, the recovered oil will in turn be converted into $\mathrm{CO}_{2}$ emissions, giving rise to a net increase of $\mathrm{CO}_{2}$ emissions to the 

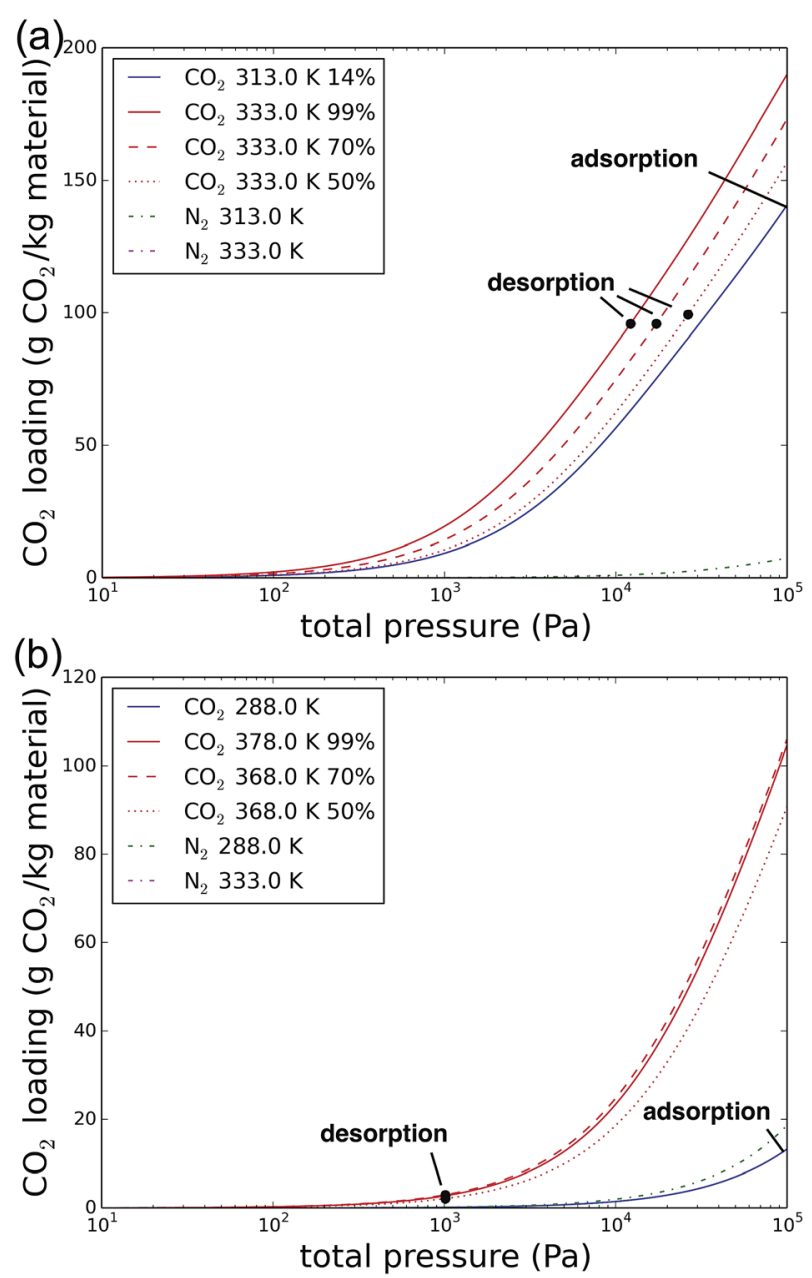

Fig. 8 The $\mathrm{CO}_{2}$ and $\mathrm{N}_{2}$ isotherms of $\mathrm{NaX}$ for carbon capture from coal-fired power plant flue gases (a) and direct air capture (b), respectively. The adsorption and different desorption conditions indicated are depending on the imposed purity of the $\mathrm{CO}_{2}$.

atmosphere. Carbon capture and utilization for EOR will only be economically viable if the price of the carbon capture technology is lower than the price to extract $\mathrm{CO}_{2}$ from natural reservoirs.

Market mechanisms alone will therefore not have a significant impact in order to lower $\mathrm{CO}_{2}$ emissions to the atmosphere. That is why a growing number of countries, regions and cities are putting a price on $\mathrm{CO}_{2}$ emissions, either through taxes or cap-and-trade mechanisms. Taxes straightforwardly provide incentives for polluters to reduce emissions, as it requires them to pay a fixed amount for each ton of $\mathrm{CO}_{2}$ emitted. Cap-and-trade mechanisms require polluters to buy units of allowed emissions, which can be traded on the market, like any other commodity. Last year, this global market traded 7 billion metric tons of $\mathrm{CO}_{2}$, a significant portion of the total emissions. At first sight, the total market for CCS 


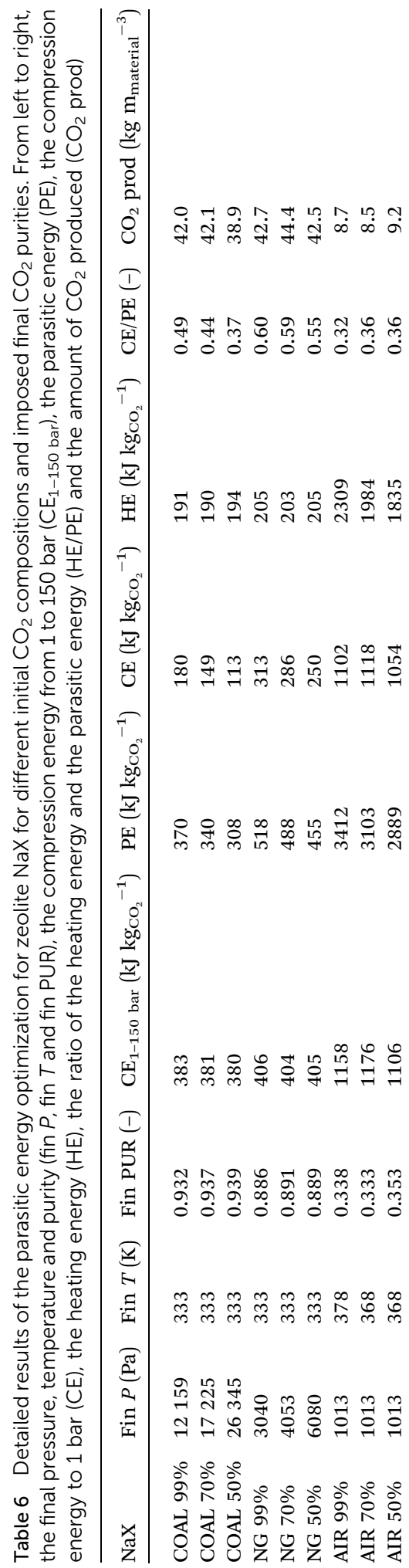


Table 7 Global $\mathrm{CO}_{2}$ emissions, traded emissions and $\mathrm{CO}_{2}$ demand, in million metric tons per year

\begin{tabular}{llll}
\hline & $\begin{array}{l}\text { Mton per } \\
\text { year }\end{array}$ & Year & Reference \\
\hline Global $\mathrm{CO}_{2}$ emissions & 36000 & 2015 & 83 \\
Traded $\mathrm{CO}_{2}$ emissions & 7000 & 2015 & 83 \\
Demand for bulk CO & 80 & 2011 & 82 \\
$\quad$ of which EOR & 50 & 2011 & 82
\end{tabular}

is two orders of magnitude larger than the market for CCU. However, it only pays off to capture and sequester $\mathrm{CO}_{2}$ emissions if the price to emit one ton of $\mathrm{CO}_{2}$ is higher than the cost of a technology that avoids the emission of one ton of $\mathrm{CO}_{2}$.

The trading prices of $\mathrm{CO}_{2}$ in Europe and California were around 8 EUR and 12 USD per metric ton of $\mathrm{CO}_{2}$ in 2015 , whereas reported CCS costs are generally a few times higher (see Table 8). Moreover, on average, $\mathrm{CO}_{2}$ emissions are priced at less than 10 USD per ton. ${ }^{83}$ As a result, there is currently no market for CCS. With the current $\mathrm{CO}_{2}$ trading prices, it is cheaper to dump $\mathrm{CO}_{2}$ into the atmosphere and pay for it, than to avoid the emissions using CCS. In view of carbon utilization, it is not straightforward to find prices for bulk $\mathrm{CO}_{2}$, as they are highly dependent on the source, and especially the distance from the source to the utilization site. We found a relatively low price for $\mathrm{CO}_{2}$ from natural reservoirs, 15-19 USD per ton, but if new pipelines have to be build, this price will increase rapidly. Likewise, some chemical plants produce $\mathrm{CO}_{2}$ with high purity and low costs (5-25 USD per ton), for instance from ammonia synthesis, but if the $\mathrm{CO}_{2}$ is not used in the

Table 8 Various prices for $\mathrm{CO}_{2}$

\begin{tabular}{lllll}
\hline & ton $\mathrm{CO}_{2}{ }^{-1}$ & Currency & Year & Ref. \\
\hline Carbon trading price & & & & \\
EU & 8 & EUR & 2015 & 84 \\
California & 12 & USD & 2015 & 85 \\
& & & & \\
CCS cost & $30-45$ & EUR & 2008 & 2 \\
McKinsey & 45 & EUR & 2008 & 3 \\
BCG & 55 & USD & 2011 & 5 \\
IEA (coal) & 80 & USD & 2011 & 5 \\
IEA (NG) & $9-44$ & USD & 2005 & 86 \\
IPCC (coal) & $16-68$ & USD & 2005 & 86 \\
IPCC (NG) & & & & \\
CO 2 production price & 51 & USD & 2010 & 87 \\
Industrial grade & $15-19$ & USD & 2011 & 82 \\
Natural reservoirs & 20 & USD & 2011 & 82 \\
Concentrated sources & $5-25$ & USD & 2005 & 88 \\
Refinery & $90-100$ & USD & 2005 & 88 \\
Consumer market & & & & \\
Social cost of carbon & 43 & USD & 2013 & 89 \\
Interagency working & & & &
\end{tabular}


proximity of the refinery, the cost will go up drastically. Moreover, when foodgrade $\mathrm{CO}_{2}$ is required, the price will also be higher than that of industrial grade, etc.

The central question in this manuscript is whether utilization at ambient pressure and lower purity further shift the economics in a more favorable direction. Since the parasitic energy is defined as the electricity loss of the power plant, the values in $\mathrm{kJ} \mathrm{kg}_{\mathrm{CO}_{2}}{ }^{-1}$ can be converted to currency, by assuming an average electricity price. In 2015, the price for electricity for industrial customers was on average 0.12 EUR per $\mathrm{kW}$ per $\mathrm{h}$ in the European Union $^{90}$ and 0.07 USD in the United States of America. ${ }^{91}$ Note that there are large differences across these regions, and that no distinction is made between the relative costs of the different fuels (coal, natural gas, nuclear, renewable). Table 9 shows the monetary cost for the different carbon capture scenarios discussed above. These values do not include the capital cost, or the cost of transportation and sequestration, which is around 10 EUR per ton of $\mathrm{CO}_{2}$.

The cost of 24 EUR per ton in Table 9 for carbon capture from the flue gas of coal-fired power plants is in agreement with the CCS costs reported in Table 8 when subtracting the transportation, storage and capital cost. The price of 14 USD is also relatively close to the 15-19 USD for $\mathrm{CO}_{2}$ from natural $\mathrm{CO}_{2}$ reservoirs, indicating that captured $\mathrm{CO}_{2}$ from coal flue gases could possibly be used for EOR. Secondly, in Table 9, the difference between coal-fired power plants and natural gas-fired power plants is much smaller than what was expected from the policy reports in Table 8. For $\mathrm{CO}_{2}$ capture directly from the air, we did not find reference prices in the literature, but the values in Table 9 are likely on the low side.

Most interestingly, not compressing the capture $\mathrm{CO}_{2}$ from 1 bar to 150 bar saves around 13 EUR or 7 USD per ton of $\mathrm{CO}_{2}$. Lowering the purity requirement from $99 \%$ to $70 \%$ or $50 \%$ can save 1-2 EUR or 1-2 USD, a modest improvement. The $\mathrm{CO}_{2}$ price of 9 EUR or 5 USD per ton from coal flue gases is very interesting for applications where 1 bar $\mathrm{CO}_{2}$ at $50 \%$ purity is desired. Finally, an interagency working group determined the US social cost of $\mathrm{CO}_{2}$ at 43 USD per ton of $\mathrm{CO}_{2}$ in 2020 assuming a $3 \%$ discount rate. ${ }^{89,92}$ At this socially desirable $\mathrm{CO}_{2}$ price, sequestration and utilization of $\mathrm{CO}_{2}$ would be economically viable.

Table 9 The minimal cost for carbon capture, assuming an average price of 0.07 USD per $\mathrm{kW}$ per $\mathrm{h}$ in the USA, or parasitic energies of the best performing materials for each source of $\mathrm{CO}_{2}$, are compared across the imposed purities

\begin{tabular}{lllll}
\hline & 150 bar, $99 \%$ & 1 bar, $99 \%$ & 1 bar, $70 \%$ & 1 bar, 50\% \\
\hline EUR & & & & \\
COAL & 24 & 11 & 10 & 9 \\
NG & 27 & 15 & 14 & 13 \\
AIR & 41 & 28 & 27 & 25 \\
USD & & & & \\
COAL & 14 & 7 & 6 & 5 \\
NG & 16 & 9 & 8 & 8 \\
AIR & 24 & 17 & 15 & 14
\end{tabular}




\section{Conclusions}

Before $\mathrm{CO}_{2}$ can be sequestered in underground reservoirs, it has to be purified to $99 \%$ and subsequently compressed to 150 bars, making up a large part of the cost for carbon capture and storage. For some examples of carbon capture and utilization however, compression to 150 bar is superfluous and the final purity requirement may be lower than $99 \%$. The use of $\mathrm{CO}_{2}$ to increase crop growth in greenhouses, algae growth for biofuel production or "Carbstone" are a few notable examples. In this manuscript, we investigate how far the parasitic energy - and therefore costs - of carbon capture can be lowered by considering less stringent final conditions. To find reliable trends, we screen a selection of over 60 materials, both synthesized and hypothetical, from a variety of material families.

First of all, we find that the compression work from 1 to 150 bar comprises up to $55 \%$ of the parasitic energy for CCS. Therefore, avoiding this compression work in a CCU application is by far the biggest possible improvement we identified. Moreover, lowering the purity requirement from $99 \%$ down to $50 \%$ further lowers the parasitic energy up to $20 \%$. This stems from the fact that $\mathrm{CO}_{2}$ can be recovered at a less strong vacuum, which requires less compression work.

When comparing different materials, two effects are at play. Across different materials, the higher the purity of the final mixture, the lower the parasitic energy requirement. For a single material however, the parasitic energy is lowered when lower purity requirements are imposed. There is a systematic distinction between the imposed purity and the final purity. We found that the $\mathrm{CO}_{2} / \mathrm{N}_{2}$ selectivity of the material, a fixed material property, and not the imposed final purity, one of the carbon capture process conditions, has the largest influence on the final $\mathrm{CO}_{2}$ purity, a result of the parasitic energy minimization. When a lower purity is imposed, the final purity does not change significantly, but the desorption pressure is higher and the compression work of the regeneration is hence lower. Therefore, a highly selective material yields a high final purity, and the carbon capture process can subsequently be operated at a lower imposed purity, thereby lowering the parasitic energy.

As a result, the best performing materials remain the same across the considered final conditions, although the relative order may somewhat shift. For carbon capture from coal flue gases, natural gas flue gases and air, these materials are Mg-MOF-74, PPN-6- $\mathrm{CH}_{2}$-TETA, and PPN-6- $\mathrm{CH}_{2}$-DETA, respectively. Zeolite $\mathrm{NaX}$ combines its commercial availability with good performance, especially for coal flue gases and natural gas flue gases.

Interestingly, omitting the 1-150 bar compression and lowering the purity requirement reduces the parasitic energy of direct air capture almost to the parasitic energy to recover $\mathrm{CO}_{2}$ at $99 \%$ purity and 150 bar from coal flue gases. Direct air capture could hence be attractive for specific cases of carbon utilization. Bear in mind that changing the purity requirement is not possible with the MEA technology, as $100 \%$ pure $\mathrm{CO}_{2}$ is stripped from the amines in the regeneration step. This underlines the extra potential of solid adsorbent carbon capture in the case of CCU.

As a conclusion, when $\mathrm{CO}_{2}$ is not sequestered at 150 bar and $99 \%$ purity, but instead utilized at ambient pressure and lower purities, the parasitic energy and associated cost of carbon capture may be reduced by almost $60 \%$. This drastically 
lowers the cost of carbon capture for utilization purposes. Moreover, the calculated price of $\mathrm{CO}_{2}$ capture from coal flue gases, for utilization at 1 bar and $50 \%$ purity ( 9 EUR or 5 USD respectively), is competitive with $\mathrm{CO}_{2}$ from natural reservoirs or refineries. This makes a strong case for carbon capture and utilization.

\section{Acknowledgements}

L. J. and V. V. S. acknowledge the Flemish Fund for Scientific Research (FWO12/ ASP/151) and BELSPO in the frame of IAP/7/05 for financial support. V. V. S. acknowledges funding from the European Research Council under the European Community's Seventh Framework Programme FP7 (2007-2013) ERC grant agreement number 240483, of the European Union's Horizon 2020 research and innovative programme under consolidator ERC grant agreement number 647755DYNPOR (2015-2020). B. S. was supported by the Center for Gas Separations Relevant to Clean Energy Technologies, an Energy Frontier Research Center funded by the U.S. Department of Energy, Office of Science, and Office of Basic Energy Sciences, under Award Number DE-SC0001015. J. M. H. was supported by the Deutsche Forschungsgemeinschaft (DFG, priority program SPP 1570).

\section{References}

1 A. S. Bhown and B. C. Freeman, Environ. Sci. Technol., 2011, 45, 8624-8632.

2 McKinsey\&Company, Carbon Capture \& Storage: Assessing the Economics, 2008, http://www.globalccsinstitute.com/publications/carbon-capture-storageassessing-economics.

3 Boston Consulting Group, Carbon Capture and Storage: A Solution to the Problem of Carbon Emissions, 2008, https://www.bcg.com/documents/ file15263.pdfs.

4 British Petroleum, BP Energy Outlook 2035, 2015, https://www.bp.com/ energyoutlook.

5 International Energy Agency, World Energy Outlook 2013 factsheet, 2013, http:// www.worldenergyoutlook.org/resources/factsheets/.

6 G. T. Rochelle, Science, 2009, 325, 1652-1654.

7 G. Rochelle, E. Chen, S. Freeman, D. Van Wagener, Q. Xu and A. Voice, Chem. Eng. J., 2011, 171, 725-733.

8 D. M. D'Alessandro, B. Smit and J. R. Long, Angew. Chem., Int. Ed., 2010, 49, 6058-6082.

9 S. Choi, J. Drese and C. Jones, ChemSusChem, 2009, 2, 796-854.

10 G. Sneddon, A. Greenaway and H. H. P. Yiu, Adv. Energy Mater., 2014, 4, 1301873.

11 A. O. Yazaydin, R. Q. Snurr, T.-H. Park, K. Koh, J. Liu, M. D. LeVan, A. I. Benin, P. Jakubczak, M. Lanuza, D. B. Galloway, J. J. Low and R. R. Willis, J. Am. Chem. Soc., 2009, 131, 18198-18199.

12 M. Fernandez, P. G. Boyd, T. D. Daff, M. Z. Aghaji and T. K. Woo, J. Phys. Chem. Lett., 2014, 5, 3056-3060.

13 N. T. T. Nguyen, H. Furukawa, F. Gándara, H. T. Nguyen, K. E. Cordova and O. M. Yaghi, Angew. Chem., Int. Ed., 2014, 53, 10645-10648.

14 B. Wang, A. P. Cote, H. Furukawa, M. O'Keeffe and O. M. Yaghi, Nature, 2008, 453, 207-211. 
15 D. Yuan, W. Lu, D. Zhao and H.-C. Zhou, Adv. Mater., 2011, 23, 3723-3725.

16 W. Lu, D. Yuan, D. Zhao, C. I. Schilling, O. Plietzsch, T. Muller, S. Bräse, J. Guenther, J. Blümel, R. Krishna, Z. Li and H.-C. Zhou, Chem. Mater., 2010, 22, 5964-5972.

17 W. Lu, W. M. Verdegaal, J. Yu, P. B. Balbuena, H.-K. Jeong and H.-C. Zhou, Energy Environ. Sci., 2013, 6, 3559.

18 T.-H. Bae, M. R. Hudson, J. A. Mason, W. L. Queen, J. J. Dutton, K. Sumida, K. J. Micklash, S. S. Kaye, C. M. Brown and J. R. Long, Energy Environ. Sci., 2013, 6, 128-138.

19 J. Kim, M. Abouelnasr, L.-C. Lin and B. Smit, J. Am. Chem. Soc., 2013, 135, 7545-7552.

20 M. W. Deem, R. Pophale, P. A. Cheeseman and D. J. Earl, J. Phys. Chem. C, 2009, 113, 21353-21360.

21 M. M. F. Hasan, E. L. First and C. A. Floudas, Phys. Chem. Chem. Phys., 2013, 15, 17601-17618.

22 L. Joos, K. Lejaeghere, J. Huck, V. Van Speybroeck and B. Smit, Energy Environ. Sci., 2015, 8, 2480-2491.

23 H.-C. Zhou, J. R. Long and O. M. Yaghi, Chem. Rev., 2012, 112, 673-674.

24 V. Van Speybroeck, K. Hemelsoet, L. Joos, M. Waroquier, R. G. Bell and C. R. A. Catlow, Chem. Soc. Rev., 2015, 44, 7044-7111.

25 J. Li, A. Corma and J. Yu, Chem. Soc. Rev., 2015, 44, 7112-7127.

26 Y.-S. Bae and R. Q. Snurr, Angew. Chem., Int. Ed., 2011, 50, 11586-11596.

27 L.-C. Lin, A. H. Berger, R. L. Martin, J. Kim, J. A. Swisher, K. Jariwala, C. H. Rycroft, A. S. Bhown, M. Deem, M. Haranczyk and B. Smit, Nat. Mater., 2012, 11, 633-641.

28 J. M. Huck, L.-C. Lin, A. H. Berger, M. N. Shahrak, R. L. Martin, A. S. Bhown, M. Haranczyk, K. Reuter and B. Smit, Energy Environ. Sci., 2014, 7, 4132-4146.

29 C. Simon, R. Mercado, S. Schnell, B. Smit and M. Haranczyk, Chem. Mater., 2015, 27, 4459-4475.

30 C. Simon, J. Kim, D. Gomez-Gualdron, J. Camp, Y. Chung, R. Martin, R. Mercado, M. Deem, D. Gunter, M. Haranczyk, D. Sholl, R. Snurr and B. Smit, Energy Environ. Sci., 2015, 8, 1190-1199.

31 L. Joos, J. A. Swisher and B. Smit, Langmuir, 2013, 29, 15936-15942.

32 S. Heylen, L. Joos, T. N. Parac-Vogt, V. Van Speybroeck, C. E. A. Kirschhock and J. A. Martens, Angew. Chem., Int. Ed., 2012, 51, 11010-11013.

33 B. Smit, J. R. Reimer, C. M. Oldenburg and I. C. Bourg, Introduction to Carbon Capture and Sequestration, Imperial College Press, London, 1st edn, 2014.

34 S. A. Scott, M. P. Davey, J. S. Dennis, I. Horst, C. J. Howe, D. J. Lea-Smith and A. G. Smith, Curr. Opin. Biotechnol., 2010, 21, 277-286.

35 S. A. Prior, G. B. Runion, S. C. Marble, H. H. Rogers, C. H. Gilliam and H. A. Torbert, HortScience, 2011, 46, 158-162.

36 H. H. Rogers, G. Runion and S. V. Krupa, Environ. Pollut., 1994, 83, 155-189.

37 C. Meyer, M. G. Wichmann and T. S. Spengler, J. Econ. Bus., 2016, 1-36.

38 D. H. Abbott and C. E. Albright, J. Laser Appl., 1994, 6, 69.

39 W. Klemm and R. Berger, Cem. Concr. Res., 1972, 2, 567-576.

40 C. Wang, L. Lü and M. Xu, J. Med. Entomol., 2012, 49, 1076-1083.

41 E. N. T. George Douglas Hobson, Introduction to Petroleum Geology, Scientific Press Limited, 1st edn, 1975.

42 E. Davidson, Process of extinguishing fires, US Pat., 1,010,870, 1911. 
43 Q. Wang, J. Luo, Z. Zhong and A. Borgna, Energy Environ. Sci., 2011, 4, 42-55.

44 A. Kumar, D. G. Madden, M. Lusi, K.-J. Chen, E. A. Daniels, T. Curtin, J. J. Perry and M. J. Zaworotko, Angew. Chem., Int. Ed., 2015, 54, 14372-14377.

45 A. L. Myers and J. M. Prausnitz, AIChE J., 1965, 11, 121-127.

46 E. W. Lemmon, M. L. Huber and M. O. McLinden, NIST Reference Fluid Thermodynamic and Transport Properties Database (REFPROP): Version9.0, 2010, http://www.nist.gov/srd/nist23.cfm.

47 S. A. Freeman, R. Dugas, D. H. Van Wagener, T. Nguyen and G. T. Rochelle, Int. J. Greenhouse Gas Control, 2010, 4, 119-124.

48 D. M. D'Alessandro, B. Smit and J. R. Long, Angew. Chem., Int. Ed., 2010, 49, 6058-6082.

49 K. Sumida, D. L. Rogow, J. A. Mason, T. M. McDonald, E. D. Bloch, Z. R. Herm, T.-H. Bae and J. R. Long, Chem. Rev., 2012, 112, 724-781.

50 J.-R. Li, J. Sculley and H.-C. Zhou, Chem. Rev., 2012, 112, 869-932.

51 J. M. Simmons, H. Wu, W. Zhou and T. Yildirim, Energy Environ. Sci., 2011, 4, 2177.

52 J. A. Mason, K. Sumida, Z. R. Herm, R. Krishna and J. R. Long, Energy Environ. Sci., 2011, 4, 3030.

53 T. M. McDonald, D. M. D'Alessandro, R. Krishna and J. R. Long, Chem. Sci., 2011, 2, 2022.

54 P. Aprea, D. Caputo, N. Gargiulo, F. Iucolano and F. Pepe, J. Chem. Eng. Data, 2010, 55, 3655-3661.

55 P. Chowdhury, S. Mekala, F. Dreisbach and S. Gumma, Microporous Mesoporous Mater., 2012, 152, 246-252.

56 P. D. C. Dietzel, R. Blom and H. Fjellvåg, Eur. J. Inorg. Chem., 2008, 2008, 36243632.

57 P. D. C. Dietzel, V. Besikiotis and R. Blom, J. Mater. Chem., 2009, 19, 7362.

58 L. Grajciar, A. D. Wiersum, P. L. Llewellyn, J.-S. Chang and P. Nachtigall, J. Phys. Chem. C, 2011, 115, 17925-17933.

59 Z. Liang, M. Marshall and A. L. Chaffee, Energy Fuels, 2009, 23, 2785-2789.

60 B. Mu, P. M. Schoenecker and K. S. Walton, J. Phys. Chem. C, 2010, 114, 64646471.

61 Z. R. Herm, J. A. Swisher, B. Smit, R. Krishna and J. R. Long, J. Am. Chem. Soc., 2011, 133, 5664-5667.

62 R. Banerjee, H. Furukawa, D. Britt, C. Knobler, M. O'Keeffe and O. M. Yaghi, J. Am. Chem. Soc., 2009, 131, 3875-3877.

63 H. Amrouche, S. Aguado, J. Pérez-Pellitero, C. Chizallet, F. Siperstein, D. Farrusseng, N. Bats and C. Nieto-Draghi, J. Phys. Chem. C, 2011, 115, 16425-16432.

64 H. Huang, W. Zhang, D. Liu, B. Liu, G. Chen and C. Zhong, Chem. Eng. Sci., 2011, 66, 6297-6305.

65 D. Yuan, W. Lu, D. Zhao and H.-C. Zhou, Adv. Mater., 2011, 23, 3723-3725.

66 R. L. Martin, L.-C. Lin, K. Jariwala, B. Smit and M. Haranczyk, J. Phys. Chem. C, 2013, 117, 12159-12167.

67 P. Bai, M. Tsapatsis and J. I. Siepmann, Langmuir, 2012, 28, 15566-15576.

68 J. W. Yoon, Y.-K. Seo, Y. K. Hwang, J.-S. Chang, H. Leclerc, S. Wuttke, P. Bazin, A. Vimont, M. Daturi, E. Bloch, P. L. Llewellyn, C. Serre, P. Horcajada, J.-M. Grenèche, A. E. Rodrigues and G. Férey, Angew. Chem., Int. Ed., 2010, 49, 5949-5952. 
69 J. Liu, P. K. Thallapally, B. P. McGrail, D. R. Brown and J. Liu, Chem. Soc. Rev., 2012, 41, 2308-2322.

70 W. Lu, D. Yuan, J. Sculley, D. Zhao, R. Krishna and H.-C. Zhou, J. Am. Chem. Soc., 2011, 133, 18126-18129.

71 W. Lu, J. P. Sculley, D. Yuan, R. Krishna, Z. Wei and H.-C. Zhou, Angew. Chem., Int. Ed., 2012, 51, 7480-7484.

72 K. S. Lackner, Energy, 2013, 50, 38-46.

73 Direct Air Capture of $\mathrm{CO}_{2}$ with Chemicals: A Technology Assessment for the APS Panel on Public Affairs, 2011, https://www.aps.org/policy/reports/ assessments/upload/dac2011.pdf.

74 W. Lu, J. P. Sculley, D. Yuan, R. Krishna, Z. Wei and H.-C. Zhou, Angew. Chem., Int. Ed., 2012, 51, 7480-7484.

75 J. Mérel, M. Clausse and F. Meunier, Environ. Prog., 2006, 25, 327-333.

76 D. Ko, R. Siriwardane and L. T. Biegler, Ind. Eng. Chem. Res., 2003, 42, 339-348.

77 K. T. Chue, J. N. Kim, Y. J. Yoo, S. H. Cho and R. T. Yang, Ind. Eng. Chem. Res., 1995, 34, 591-598.

78 P. Nugent, Y. Belmabkhout, S. D. Burd, A. J. Cairns, R. Luebke, K. Forrest, T. Pham, S. Ma, B. Space, L. Wojtas, M. Eddaoudi and M. J. Zaworotko, Nature, 2013, 495, 80-84.

79 O. Shekhah, Y. Belmabkhout, Z. Chen, V. Guillerm, A. Cairns, K. Adil and M. Eddaoudi, Nat. Commun., 2014, 5, 4228.

80 Transparency Market Research, Global Synthetic Zeolite Market, http:// www.transparencymarketresearch.com/pressrelease/synthetic-zeolites-market. htm.

81 B. Yilmaz, N. Trukhan and U. Müller, Chin. J. Catal., 2012, 33, 3-10.

82 Accelerating the Uptake of CCS: Industrial Use of Capture Carbon Dioxide, 2011, https://www.hub.globalccsinstitute.com/publications/.

83 State and Trends of Carbon Pricing, 2015, http://www.worldbank.org/content/ $\mathrm{dam} /$ Worldbank/document/Climate/State-and-Trend-Report-2015.pdf.

84 European Emission Allowances-Global Environmental Exchange, 2015, https://www.eex.com/en/market-data/emission-allowances/spot-market/ european-emission-allowances.

85 California Carbon Dashboard, 2015, http://www.calcarbondash.org.

86 IPCC Special Report on Carbon Capture and Storage, 2005.

87 Carbon Dioxide Enhanced Oil Recovery - Untapped Domestic Energy Supply and Long Term Carbon Storage Solution, 2010, https://www.netl.doe.gov/file/ \%20library/research/oil-gas/small_CO2_EOR_Primer.pdf.

88 Carbon Dioxide Apps Are Key In Ethanol Project Developments, 2011, http:// www.ethanolproducer.com/articles.

89 Social Cost of Carbon for Regulatory Impact Analysis? Under Executive Order 12866, 2013, http://www.1.usa.gov/18ftAsH.

90 Energy price statistics, 2015, http://www.eceuropa.eu/eurostat/statisticsexplained/index.php/Energy_price_statistics.

91 Electric Power Monthly, 2015, http://www.eia.gov/electricity/monthly/pdf/ epm.pdf.

92 A. Fraas, R. Lutter, S. Dudley, T. Gayer, J. Graham, J. F. Shogren and W. K. Viscusi, Science, 2016, 351, 569. 